\title{
The Use Of Market Intelligence Tools To Optimize The Economic Impact Of A Chronic Disease In Mexico
}

Jaqueline Alejandra Haces Arce, Ph D candidate, Universidad Anáhuac México Sur., México

\begin{abstract}
The pharmaceutical products market in Mexico involves four main actors: health providers, health payers, patients and pharmaceutical companies. The relationship between health providers and the pharmaceutical companies that supply the products required to prevent and treat illnesses is of particular interest. This relationship can be described within the frame of the treatment of diabetes mellitus (DM), a major health issue in most countries, and an urgent one in Mexico. The financial impact of the treatment of diabetes could be optimized through the use of the tools provided by market intelligence systems and best clinical practices. These results would also have an impact on major health metrics for the relevant population.
\end{abstract}

Keywords: Disease burden, Pharmaceuticals, Diabetes Mellitus, Healthcare, Market Intelligence, Health Metrics.

\section{INTRODUCTION}

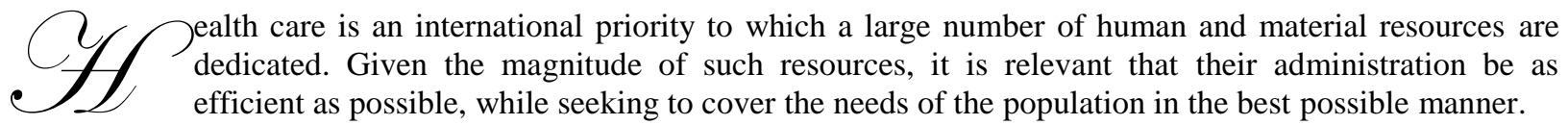

One area of opportunity in the administration of resources for the health sector in Mexico lies in the use of market intelligence methods in order to solve issues such as:

- $\quad$ Financial resource allocation.

- $\quad$ Demand planning.

- $\quad$ Social marketing.

- $\quad$ Treatment guidelines.

Diabetes is a chronic disease that affects more than 170 million people worldwide, and this number is expected to double by 2030 (WHO, 2000). In Mexico, there are 2.2 million people living with diabetes, and the projected figure for 2030 is 6.1 million. It is currently the first cause of death in the country, and one public health program (PrevenIMSS) estimates that 400 new cases are diagnosed daily.

The financial burden for of this disease is a threat to Mexico's health system, and the country's economy as a whole. The cost of treatment can be roughly divided into direct and indirect costs. Direct costs are those applied to the purchase of drugs to prevent glycemic levels from going up, and when this fails, to treat the ensuing complications. They also include hospital costs for diabetes-related complications and medical and nurse fees. Indirect costs include the loss of productivity due to the disease, not only for the patient but also for caregivers, and they are also related to the frequency of complications that lead to temporary and permanent disability. The medical profession has long been aware of the fact that complications arise when glucose levels are not adequately controlled, but the costs associated with such complications have not been systematically measured in Mexico. 
Market intelligence tools such as market research, focus groups and in-depth interviews have been used for some time by the pharmaceutical industry in the planning and controlling stages of its commercial process, and they can be extremely useful for the health system in helping to determine the total cost of treatment for diabetes and other chronic diseases, thus optimizing the use of financial resources.

\section{MATERIALS AND METHODS}

Information was gathered through research in major academic databases (Ebsco, ProQuest, PubMed, Emerald) of relevant studies related to the treatment of diabetes, focusing on the pharmacological treatment of the disease and circumscribed whenever possible to the current situation at the Mexican Institute of Social Security (Instituto Mexicano del Seguro Social, IMSS). Other topics researched include: health services marketing, demand planning, market intelligence, cost of treatment and patient compliance.

The data presented was supplemented by conducting interviews with experts in the fields of medicine and pharmaceutical marketing in order to get views leading up to a better understanding of the management of the pharmaceutical products market within this context.

\section{THE ECONOMIC BURDEN OF DIABETES}

Around the world, the cost of medical care has been rising and this creates resource allocation problems that call for economic evaluations to become an integral part of disease management. Diabetes mellitus is a very frequent and challenging pathology and its complications can lead to disability, reduced life expectancy and huge healthcare costs (Pagano, et al., 1999). These costs arise mainly from direct healthcare activities and loss of productivity and force health services to improve their quality of care while paying attention to the financial impact of the disease.

The following expert opinions underline the need to apply economic and financial measurements to the evaluation of the different courses of treatment currently available for diabetes patients:

Johnson, et al. (2006) describe that information on the burden of health conditions, be it in epidemiological or economic terms, is of great interest for those responsible of establishing policies. This information is relevant because it enables administrators and physicians to make informed decisions regarding resource allocation for the management of existing and foreseen diseases, and also because it gives them tools to justify health promotion and prevention programs.

On the relevance of treating diabetes, from a cost-effective standpoint, Kapur (2007) believes that effective intervention should include primary and secondary prevention and that everyone involved in diabetes care needs to know the costs related to the treatment of this illness. Furthermore, this author states that inadequate treatment of diabetes is very costly, which is a very interesting point of view, particularly in developing countries where cost contention is of the utmost importance.

Ramachandran, et al. (2007) highlight the need to have consistent data on the cost burden of diabetes given the fact that, particularly in developing countries, there are isolated and non-comparable data on this regard.

Adding to the cost issue, Zhang, et al. (2004) believe future studies should favor cost-saving interventions, like intensive control of blood pressure, in order to offer economically feasible solutions to diabetes treatment. Another effective intervention lies in the control of glucose levels through appropriate courses of action for each particular patient.

In all cases, the bottom line is that for diabetes patients, a strict metabolic control achieved by early interventions is more cost-effective than the management of the resulting complications when initial treatment fails to reach its goals. 


\section{DIABETES MELLITUS}

Diabetes mellitus (DM) can be defined as a metabolic disease produced by defects in the secretion of insulin, inadequacies in its action, or both. It constitutes a major health problem in Mexico, with high incidences and prevalences across the country. It is also one of the main causes of medical consultation and a treatment challenge for both patients and physicians (Oviedo Mota, et al., 2003).

Manifestations of DM include polyuria (frequent need to urinate), polydipsia (increased thirst), weakness and weight loss, but some patients might arrive at the doctor's office with more serious complications derived from chronically high levels of glucose (Fauci (Ed.), et al., 1998), such as the following:

a) Retinopathy

A progressive degeneration of the retina, it is the most frequent cause of blindness in adults. Intensive treatment to achieve normal levels of glucose can prevent or delay its onset.

b) Neuropathy

It constitutes an irreversible complication of diabetes, which manifests itself through alterations of reflexes, sensibility, and the perception of pain, tactile sensations, temperature, vibration and position.

c) Nephropathy

Characterized by a gradual dysfunction of the kidneys, diabetic nephropathy is the main cause of chronic kidney disease. Again, strict glycemic control can delay its onset and progression.

d) Cardiovascular disease

This constitutes the main cause of death in diabetic patients. It can be prevented by closely monitoring the patient for hypertension and renal function, which are two significant risk factors.

e) Hypertension

It affects more than half of the people with diabetes and is a major risk factor for cardiovascular disease and microvascular complications, such as retinopathy and nephropathy.

f) Dyslipidemia

Defined by deficient levels of cholesterol and triglycerides, it also represents an important risk factor for the development of vascular disease.

\section{TREATMENT OF DIABETES}

People diagnosed with diabetes mellitus should be treated by a multidisciplinary team that includes a nurse, a nutritionist, and psychological experts under the guidance of the treating physician. As with many other metabolic diseases, specialists recommend to start treatment of diabetes with dietary and exercise recommendations. It is important to mention that even though there are two distinct types of DM (Type I and Type II), many studies consider it as one disease (Pagano, et al., 1999) and for analysis purposes it will be considered as such throughout this document.

Education of the patient is key for treatment success as is the active participation of his/her family. The initial diet and exercise programs aim to maintain glucose levels within a strict range to prevent or reduce the risk of complications. Exercise programs should be carefully designed after the medical evaluation of the patient's general 
health status. All plans should be targeted to the individual needs of the patient, and close monitoring is essential to ensure compliance and reduce the likelihood of progression, or at least delay it as much as possible.

If dietary and exercise recommendations fail to achieve an adequate control of glucose levels, then the patient can receive a set of medications known as "oral hypoglycemic agents" (Oviedo Mota, et al., 2003), which include the following:

1. Sulfonylureas:

These drugs reinforce the secretion of insulin, and work particularly well in recently diagnosed, non-obese patients. An example is glibenclamide, which is also one of the most widely prescribed drugs for diabetic patients at the IMSS.

2. Biguanides:

Used for the treatment of obese patients, they lower levels of plasma glucose and also cholesterol and triglycerides. An example is metformin, which reduces the production of hepatic glucose and increases the muscle's sensibility to insulin. It is sometimes used in combination with glibenclamide.

3. Alpha-glucosidase inhibitors:

Their main effect is to lower glucose levels after meals. They interfere with carbohydrate digestion and delay glucose absorption.

When the highest dose of oral medications fails to control glucose levels, direct administration of the hormone insulin is required. In Mexico, there are 3 kinds of insulin, according to speed of action, and in every case the dose should be adjusted to each individual patient. Self-monitoring glucose devices are particularly helpful to ensure good metabolic control.

\section{IMSS}

The biggest health provider in the country belongs to the public health sector and is represented mainly by the Mexican Institute of Social Security (Instituto Mexicano del Seguro Social, IMSS) founded in 1943 by a group of employees, employers, and the Federal Government. It is the largest social security institution in Latin America and has a workforce of over 370,000 employees across the country. Nowadays, the IMSS faces difficult conditions that threaten its viability, and its administration is focused on making the institute more modern and efficient in order to increase earnings and reduce non-prioritary expenses (IMSS, 2002).

The IMSS reports a constantly increasing number of patients treated due to diabetes and its complications. This increase might be caused by a higher incidence of the disease, and also by the longer life expectancies of patients (Escobedo de la Peña and Rico Verdín, 1996). Two additional factors that complicate diabetes management at this institute are the following:

a) The lack of experience and knowledge of some of the first-contact physicians that diagnose and treat diabetes. These are usually general practitioners of small clinics and hospitals (catalogued as being the "first-level" of contact within the system) who, due to high workloads and sometimes lack of motivation, don't have enough time to educate themselves and their patients (E. Rodríguez, Personal Communication on March 14, 2008). These limitations result in poor metabolic control of patients and therefore are associated with higher incidences of complications that require hospital treatment at higher levels of attention (second- and third-level hospitals) (Rodríguez-Moctezuma, et al., 2003).

b) The low treatment compliance observed in almost half of diabetes patients (Durán-Varela, et al., 2001). Again, mostly due to low baseline education levels of the patients and to the very little and inaccurate information they receive about their disease, these patients do not assign sufficent priority to their treatment 
and control. This factor also has a negative impact on the development of serious diabetes complications that could be otherwise prevented or delayed.

These factors contribute to the high reported number of DM complications (Sabag-Ruiz, et al, 2006) and the frequent hospitalizations related to this disease within the institute (Membreño Mann and Zonana Nacach, 2005). Both occurrences reflect the need for improvement in the treatment of diabetes patients and also constitute areas of opportunity to improve the institute's budget allocation.

The IMSS currently does not engage in market research to find out what its customers need (we understand customers here as the physicians who have the institute's patients under their care); and because of the lack of a market intelligence department, drug purchases are often not made according to the existing epidemiology. This might be an issue that leads to poor glycemic control in the diabetic patient, which, when chronic, leads to costly complications that increase the burden of the disease, both in social and economic terms.

\section{ACCESS TO DRUGS}

The access to life-improving drugs and their quality is an international source of debate. The allocation of health budgets relies on a number of factors, among which is the perception of utility of the drugs themselves and the relationship of the health sector with the pharmaceutical industry that supplies these drugs. By reviewing reports of several institutions comprising the health sector in Mexico, it can be acknowledged that there is a sub-optimal use of expense budgets, and this generates a situation where not all the needs of the population can be adequately covered (L. Jasso, Personal Communication, September 21, 2007).

It is expected that the pressure on health expenditure will increase worldwide and it will come from different sources according to the Organization for Economic Cooperation and Development (OECD, 2006):

- $\quad$ The population age, although it might not contribute as much as expected.

- $\quad$ The increase in earnings, because the population will demand better quality in healthcare.

- $\quad$ Prices assigned to health services, which are expected to rise at a higher rate than the general price level.

- $\quad$ The arrival of new treatment options, which should be carefully evaluated.

Health expenditure in Mexico is comprised by what society pays for through taxes and what comes directly out-of-pocket. The former is called public expenditure and is exercised by all public institutions that are part of the health system the latter is the private expenditure and includes the payments made by families for their own healthcare (Secretaría de Salud, 2006).

While there is no direct relationship between health expenditure and the results of the healthcare system, it could be assumed that these results would improve with increased and better managed resources because more of the population's needs would then be covered. However, sometimes health interventions lack efficiency and therefore this cannot be actually demonstrated (Secretaría de Salud, 2006).

\section{HEALTH SERVICES MARKETING}

As a tool to help in the management of health expenditure, and therefore improve the general situation of the pharmaceutical products market, it would be useful to consider the alternatives offered by the discipline of health services marketing. Marketing (in general) consists of identifying and satisfying the needs of people and society, in a profitable manner (Kotler, 2006). A branch of this discipline is services marketing, which takes place when some or all of the following conditions are met:

- $\quad$ Customers do not own services.

- $\quad$ The market consists of service products, which are temporary and cannot be inventoried.

- Value creation is dominated by intangible elements.

- Customers might be involved in the production process.

- $\quad$ Other people can be part of the final product. 
Within the context of services marketing, Health Services Marketing can be classified as a "people process" activity since a high level of participation is demanded from patients (when receiving treatment at a hospital, for example) and the result is a customer that reaches the desired objective of a better health status (ideally). This means that the customer (or patient) undergoes a process in order to obtain a desired service. Other examples of people processes are: transportation, restaurants, hotels, etc.

Besides people processes, services marketing encompasses possession processes (like repair shops and cleaning services), mental stimuli processes (promotion, education, art), and information processes (banks, insurance companies, legal services) (Lovelock, 2004).

The marketing mix for the marketing of services adds three new elements to the traditional marketing mix. Besides Product, Price, Place and Promotion, it includes Processes, People, and Physical Environment. Two other essential factors to consider when analyzing the management status of a product or service are strategic planning and the supply/demand balance.

On this last issue, there is a need to apply effective strategies to minimize potential losses due to supply/demand imbalances, and a tool to face this challenge lies in the knowledge and use of market intelligence activities. These activities can collaborate in demand planning and forecasting and therefore reduce the frequency of unexpected imbalance situations, which are usually very costly. In the past decade, there has been great interest in conducting studies to try to explain how the application of market intelligence tools to understand demand trends can improve the financial results of organizations by reducing losses due to these imbalances (Shemwell, 1994).

\section{MARKET INTELLIGENCE}

According to Cornish (1997), Market Intelligence can be defined as the process of acquiring and analyzing information in order to understand the market, determine its needs and preferences present and future, as well as its attitudes and behaviors, and evaluate environmental changes that might affect the size and nature of said market in the future.

Market research is a critical part of market intelligence systems; it allows the improvement of the decisionmaking process by providing relevant, precise and timely information. The use of databases as analytical tools includes the use of statistical techniques, modeling and results that generate useful information that helps in market planning and budget setting (Kumar, 1999).

Market research activities include identifying, collecting, analyzing and spreading information in a systematic and objective manner with the purpose of assisting the decision-making process. This is particularly important for administrative decisions related to problem identification and those needed to take advantage of market opportunities. There is a current trend towards an integral view of market intelligence, oriented to the solutions that market research can offer (Tan Tsu Wee, 2001). The goal of the organization must be clear: to maximize profitability (Lackmann, 2000) and, for health services, to improve productivity and outcomes.

In spite of all the evidence, health organizations do not yet allocate a relevant share of their budgets to market research. Some private hospitals in Mexico have started to show an interest in market orientation, by seeking tools used by consumer industries to try to understand the problems and opportunities that surround them. Still, in a study from the past decade where a group of hospital managers was interviewed (Loubeau, 1998), most of them reported no investment at all in market research to follow-up on the effectiveness of promotion activities carried out by their own institutions.

This same study found that even in hospitals that did engage in market research, they failed to make use of all of its benefits in their daily administration duties. It is now recommended to invest in the optimization of this tool to enhance the decision-making process.

Another issue worth mentioning refers to budget allocation. During the budget definition process in every industry, there's a need for a group of people capable of communicating with the rest of the organization in order to 
gather the necessary market intelligence. The abilities of this group should include: quantitative, informatics, and communication skills, as well as business knowledge and process management (Lapide, 2003). There are currently no reports of such a group within the budget allocation process at the IMSS.

In an industrial context, if a company doesn't have the information needed to accurately evaluate its own strategic situation, it is very unlikely that it will be able to make strategic decisions that will maximize its profitability (Makadok, 2001). These concepts can be applied to the administration of health institutions, and the impact of market intelligence on their productivity can be measured.

\section{HEALTH METRICS}

A practical way of measuring the results and productivity of a healthcare institution is through health metrics. These are outcome measures that reflect the efficiency of the organization through well-being indicators in the relevant population.

In the near future, it is foreseen that healthcare, particularly the care of chronic diseases, will become very relevant worldwide. Health sector purchasers will be responsible to their authorities for cost control and to the patients for the quality and accessibility of the health services they provide (OCDE, 2006).

In this regard, those decisions that favor lower cost alternatives will be rewarded. It is well known, for example, that ambulatory care is generally less expensive than hospital care. It can be expected, then, that interventions to limit the need for hospital stays will improve an institution's financial status. In the case of patients with diabetes, this could be achieved by establishing the infrastructure needed to ensure good glycemic control, an ambulatory intervention that can effectively reduce complications that require costly hospital stays. This infrastructure should include access to drugs as well as education programs for all involved.

To provide a relevant framework for market management analysis, an integral definition of health services must include the following:

- A clear description of the costs and benefits associated with ambulatory care.

- $\quad$ Market information for the cases when hospital care is demanded.

- An assessment of the human resources available.

- Enforceable guidelines on the use of pharmaceuticals used to prevent and treat illnesses.

Countrywide, Mexico spends 33\% of its total health expenditure in hospital care, $31 \%$ in ambulatory care and $22 \%$ in pharmaceutical products (OECD, 2005). In comparison with OCDE country averages, the pharmaceutical investment is marginally higher and the hospitalization expenditure is marginally lower. These trends should be reflected equally in the public and private markets, but experience tells us that this is not the case and the public sector spends more on hospital care and less in pharmaceutical products.

In the health system report created by OCDE, there's an important reference made to the quality of health services in Mexico, which is perceived as not always being up to international standards. This probably arises from the fact that public hospitals and clinics often don't have the qualified personnel and necessary resources to provide good health services. Additionally, the epidemiological transition from contagious diseases into chronic illnesses related to advanced age of the population presents a new set of challenges for the system, and appropriate monitoring and control metrics are not always in place.

The higher incidence of chronic diseases in Mexico seems to be associated with a current trend towards unhealthy nutritional habits and an increasingly sedentary lifestyle that is reflected in the growing number of patients with diabetes that seek medical care each year. Diabetes has thus become the leading isolated cause of death in the country (OECD, 2005).

As an answer to the challenges faced by the health system, particularly in the public sector, there have been some government initiatives that seek to include result measurements in terms of service quality. A confounding 
factor is the high cost of administrative services related to the health sector that represent $23 \%$ of the total budget of the Health Ministry and the State Services of Health, as well as 17\% of total IMSS expenditure.

Great budget limitations are then placed upon the system and their effect is deeply felt in the capacity to purchase health-related materials and medications, more than in administrative areas. The lack of proper drugs to treat diseases is one of the areas that generate the most dissatisfaction among service users. The supply issue is further increased by a centralized and inefficient distribution of drugs and medical materials.

Productivity measures tend to be complicated when applied to services because sometimes results are difficult to define, and healthcare services are no exception. It is important then to seek a metric as standardized as possible in order to make quality and efficiency comparisons for services, such as healthcare.

One example of such measurements are end-result metrics for diabetes patients, even when there is no current consensus about which are the best result indicators for these cases (Smith, 1996). There are, however, some traditional outcome measures that are considered relevant in the determination of service quality in a hospital setting.

These measures include:

- $\quad$ Mortality.

- $\quad$ Length and number of hospital stays.

- $\quad$ Amount of complications that require treatment (morbidity).

- $\quad$ Required in-patient and out-patient procedures.

They are also considered more relevant and consistent (Finkelstein, 1997) than other, patient-centered measures like:

- Treatment satisfaction.

- $\quad$ Functional state.

- $\quad$ Time needed to resume work.

Some publications also point out that the success of a social marketing program is usually measured in terms of mortality reduction, which is then considered then as an important metric in this setting (Anonymous, 2002).

Regarding life expectancy as a general indicator of health, some international studies suggest that better access to drugs can constitute an effective strategy to diminish global health costs. This stems from the fact that an increase in pharmaceutical spending is compensated by the decrease in other health costs, without affecting the health of the population as a recent Canadian study demonstrates (Crémieux, 2007).

\section{GOVERNMENT INITIATIVES}

The main government plan of action in Mexico is named Plan Nacional de Desarrollo (National Development Plan) and its version for 2007-2012 includes some initiatives that are relevant to the optimization of resources used for the treatment of chronic illnesses, such as diabetes. It recognizes that the longer life expectancy of the population brings about a change in the main causes of disability and death. Today, the main culprits are nontransmissible diseases and lesions. One of the main illnesses associated with longer living is diabetes which, along with hypertension and accidents, represents $85 \%$ of all deaths in the country (Gobierno de los Estados Unidos Mexicanos, 2007).

There is also mention in the Plan of the high cost and complexity of treating diabetes, and this realization brings it into the spotlight as a highly demanding need of the population. Obesity, poor nutritional habits and lack of exercise are related to heart disease and diabetes, which together account for $32 \%$ of deaths in women and $20 \%$ in men. The supply of drugs to prevent and control diseases has seen an improvement in ambulatory centers, but not yet in hospitals. These worries are reflected in the following sections of the Plan: 
- $\quad$ Strategy 5.1 of the Health section of the Plan proposes to create an integral system to improve the quality of medical services, focusing particularly in the timely supply of drugs. It seeks to optimize drug expenditure in public health institutions to ensure drug safety and efficacy and to institutionalize the analysis, design and evaluation processes of the pharmaceutical policy.

- $\quad$ Objective 8 in the same document is to ensure that health contributes to overcome poverty and support human development in the country, particularly by making sure that work environments are healthy and focusing on the prevention and control of invalidating diseases and the control of addictions. The promotion of healthy lifestyles will be paramount to be successful in these efforts, as well as the availability of early diagnostic tools and appropriate treatments for chronic disease.

These official statements lay the foundation for a deeper understanding of the social and implications of diabetes, its treatment and management in the Mexican population. The success of these initiatives will depend on their diligent implementation and control.

\section{DISCUSSION}

Market intelligence can be used as a competitiveness tool in the marketing of health services. Its main impact lies in the demand planning process which, when based on market intelligence systems, can improve budget allocation and resource management for the IMSS as well as other public health institutions in Mexico.

A critical issue in the healthcare equation is the availability of pharmaceutical products. This, along with appropriate education programs for both patients and caregivers, will most likely facilitate appropriate courses of treatment, which in turn can be expected to have a positive effect on health outcome metrics such as mortality, morbidity and life expectancy.

This relationship is particularly visible in the case of diabetes mellitus where good metabolic control in the form of normal glycemic levels effectively delays or even avoids the development of complications. Once it is established that the treatment of these complications is a lot more costly than their prevention, both in social and economic terms, the rationale for investing in metabolic control strategies becomes clear.

In order to implement changes in the way purchases are made in public institutions, we first need to understand the dynamics of the pharmaceutical products market in Mexico. A general feeling of distrust has divided both sides of this market, making it difficult to transfer to health institutions those strategies that have proved successful and worthwhile to the pharmaceutical industry. Careful policies need to be established in order to improve this relationship and open up the way for shared learning.

Through careful marketing services analysis in the health sector in Mexico, areas where substantial savings can be made will be identified and the resources freed by the resulting strategies can be used to tend to other urgent health needs of the population.

\section{CONCLUSION}

In the current national and international environment, it is of paramount importance to evaluate the current processes of the IMSS regarding its relationship with the pharmaceutical industry, its demand planning structure and its purchasing needs. This will allow for particular recommendations to be made on the best implementation strategy to ensure that the institute takes advantage of current administrative tools to improve its productivity and results.

The analysis of health metrics and their relationship with treatment courses is a key step in this process because it will help establish clear guidelines for treatment, and will also serve as a baseline of what educational programs must strive to achieve. 
The analysis of healthcare services is an important competitiveness factor that can help improve the position of Mexico in an international setting; not just for the health of patients, but for the country's economic development as well.

\section{AUTHOR INFORMATION}

Jaqueline Haces Arce is a Food Chemist and MBA with a specialization in Financial Management. She is currently a PhD student (Administration) at the Universidad Anáhuac - México Sur working in the analysis of the economic burden of diabetes in Mexico and its consequences on the country's competitiveness. She has been working in the pharmaceutical industry for the past 13 years, in the marketing, medical and business performance departments. Her current responsibilities as Business Performance Manager at Roche Mexico include marketing metrics and incentive management for the sales force. Her research interests include corporate social responsibility, health economics and outcome metrics.

\section{REFERENCES}

1. Anonymous. (2002) Information to die for. Marketing Health Services, 22, 2, 40.

2. Cornish, S. L. (1997) Product innovation and the spatial dynamics of market intelligence: does proximity to markets matter? Economic Geography, 73, 2, 143-165.

3. Crémieux, P-Y. et al. (2007). Do drugs reduce utilisation of other healthcare resources?

Pharmacoeconomics, 25, 3, 209-221.

4. Durán-Varela, B.R., Rivera-Chavira, B., Franco-Gallegos, E. (2001) Apego al tratamiento farmacológico en pacientes con diagnóstico de diabetes mellitus tipo 2. Salud Pública de México, 43, 3, 233-236.

5. Escobedo de la Peña, J., Rico Verdín, B. (1996) Incidencia y letalidad de las complicaciones agudas y crónicas de la Diabetes Mellitus en México. Salud Pública de México, 38, 4, 236-242.

6. $\quad$ Fauci, A.S. (Ed)., et al. (1998) Harrison's Principles of Internal Medicine. Companion Handbook. McGraw Hill Health Professions Division, USA, p. 943.

7. Finkelstein, B.S., Silvers, J.B., Rosenthal, G.E. (1997) The importance of outcomes data in health care decision making and purchasing. Marketing Health Services, 17, 2, 52.

8. Gobierno de los Estados Unidos Mexicanos. (2007) Plan Nacional de Desarrollo 2007-2012. Presidencia de la República. Poder Ejecutivo Federal, México, pp. 160-176.

9. IMSS (2002) Información institucional. Información recuperada el 21 de Marzo de 2008 de la página: http://www.imss.gob.mx/IMSS/IMSS_SITIOS/IMSS_06/institucion/index_elIMSS.htm

10. Johnson, J.A., Pohar, S.L., Majumdar, S.R. (2006) Health care use and costs in the decade after identification of type 1 and type 2 diabetes: a population-based study. Diabetes Care, 29, 11, 2403.

11. Kapur, A. (2007) Economic analysis of diabetes care. Indian Journal of Medical Research, 125, 3, 473.

12. Kotler, P., Keller, K.L. (2006) Dirección de Marketing. 12a ed., Pearson, México, p. 5.

13. Kumar, V., Aaker, D.A., Day, G.S. (1999) Essentials of Marketing Research. John Wiley \& Sons, Inc. New York, USA, pp. 1, 578, 581.

14. Lackman, C., Saban, K., Lanasa, J. (2000) The contribution of market intelligence to tactical and strategic business decisions. Marketing Intelligence \& Planning, 18, 1, 6-8.

15. Lapide, L. (2003) Organizing the forecasting department. The Journal of Business Forecasting Methods \& Systems, 22, 2, 20.

16. Loubeau, P., Jantzen, R. (1998) Marketing research activities in hospitals. Marketing Health Services, 18, 1, 13.

17. Lovelock, C., Wirtz, J. (2004). Services Marketing. People, Technology, Strategy. $5^{\text {th }}$ ed. Pearson Prentice Hall. USA. pp. 9-15.

18. Makadok, R.; Barney, J. B. (2001) Strategic factor market intelligence: an application of information economics to strategy formulation and competitor intelligence. Management Science, 47, 12, 1621-1639.

19. Membreño Mann, J.P., Zonana Nacach, A. (2005) Hospitalización de pacientes con diabetes mellitus. Causas, complicaciones y mortalidad. Rev Med IMSS, 43, 2, 97-101.

20. OECD (2005) OECD Reviews of Health Systems. Mexico. Organisation for Economic Co-operation and Development. Paris, France. pp. 55-100. 
21. OECD (2006) OECD Economic Outlook 2006. Organisation for Economic Co-operation and Development. Paris, France. pp. 145-155.

22. Oviedo Mota, M.A., et al. (2003) Guía clínica para el diagnóstico y tratamiento de la diabetes mellitus tipo 2. Rev Med IMSS, 41, S27-S46.

23. Pagano, E., et al. (1999) Costs of diabetes. A methodological analysis of the literature. Pharmacoeconomics, 15, 6, 583-595.

24. Ramachandran, A., et al. (2007). Increasing expenditure on health care incurred by diabetic subjects in a developing country. Diabetes Care, 30, 2, 252.

25. Rodríguez-Moctezuma, R., et al. (2003) Factores de los médicos familiares asociados al control glucémico de sus pacientes con diabetes mellitus. Gac Méd Mex 139, 2, 112-117.

26. Sabag-Ruiz, E., et al. (2006) Complicaciones crónicas de la diabetes mellitus. Prevalencia en una unidad de medicina familiar. Rev Med IMSS, 44, 5, 415-421.

27. Secretaría de Salud. (2006) Las Cuentas de Salud en México 2001-2005. Subsecretaría de Innovación y Calidad. Dirección General de Información en Salud. p. 11, 21.

28. Shemwell, D.J.Jr., Cronin, J.J.Jr. (1994) Services marketing strategies for coping with demand/supply imbalances. The Journal of Services Marketing, 8, 4, 14-24.

29. Smith, M.C. (Ed) (1996). Pharmaceutical Marketing in the 21st Century. Pharmaceutical Products Press. NJ, USA. p. 261.

30. Tan Tsu Wee, T. (2001) The use of marketing research and intelligence in strategic planning: key issues and future trends. Marketing Intelligence \& Planning, 19, 4, 245-253.

31. WHO (2000) Country and Regional Data for the Prevalence of Diabetes Mellitus. World Health Organization.

32. Zhang, P., et al. (2004) Application of economic analysis to diabetes and diabetes care. Annals of Internal Medicine, 140, 11, 972. 
NOTES 